Journal of Educational Technology

\& Online Learning

Volume 3 | Issue 2 | 2020

http://dergipark.gov.tr/jetol

\title{
Book Review: Utilizing Technology, Knowledge, and Smart Systems in Educational Administration and Leadership
}

Can GÜLDÜREN ${ }^{\mathrm{a}}$

a can.gulduren@ufuk.edu.tr; Ufuk University, Ankara, Turkey; ORCID: 0000-0002-9048-1228

Doi: 10.31681 /jetol.687001

Suggested citation: Güldüren, C. (2020). Book Review: Utilizing Technology, Knowledge, and Smart Systems in Educational Administration and Leadership. Journal of Educational Technology \& Online Learning, 3(2), 177-182.

\begin{tabular}{|c|c|}
\hline Article Info & Abstract \\
\hline Received: 01.02 .2020 & $\begin{array}{l}\text { Utilizing Technology, Knowledge, and Smart Systems in Educational Administration and } \\
\text { Leadership is edited by Mehmet Durnali. The book was published in } 2019 \text { by IGI Global. }\end{array}$ \\
\hline Accepted: 17.03 .2020 & $\begin{array}{l}\text { The book has xxviii+364 pages. The ISBNs of the book for different versions are; } \\
\text { ISBN13: } 9781799814085 \text {, ISBN10: } 1799814084 \text {, EISBN13: } 9781799814108 \text {. DOI }\end{array}$ \\
\hline
\end{tabular}

Book Review Keywords: Gamification, Distance and Adult Learning, M-Learning, Computer Applications, Classroom Management, E-Curriculum.

\section{INTRODUCTION}

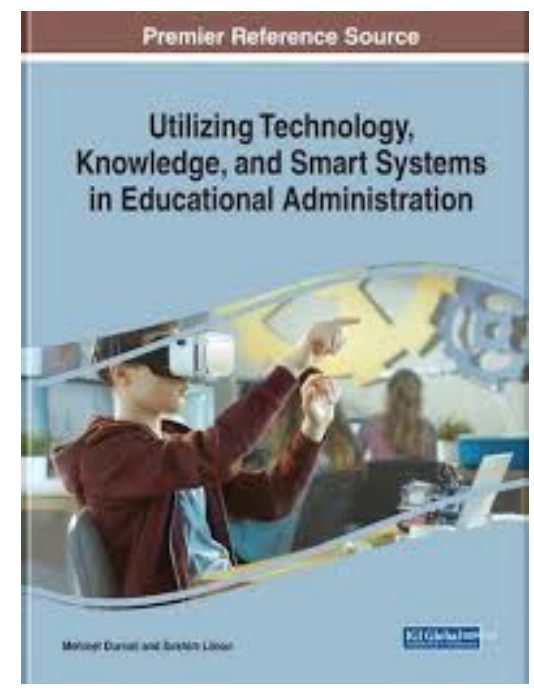

Utilizing Technology, Knowledge, and Smart Systems in Educational Administration and Leadership is edited by Mehmet Durnali. The book was published in 2019 by IGI Global. The book has xxvi+364 pages. The ISBNs of the book for different versions are; ISBN13: 9781799814085 , ISBN10: 1799814084, EISBN13: 9781799814108. DOI number of the book is $10.4018 / 978-1-7998-1408-5$.

Within educational organizations, administration and leadership are relied upon for the allocation of resources as well as the optimization of processes that can include data storage, knowledge management, and decision making. To support these expectations, technologies, knowledge, and smart systems must be put into place that allow administrators and leaders to accomplish these tasks as efficiently as possible. Utilizing Technology, Knowledge, and Smart Systems in Educational Administration and Leadership is an academic research book that examines knowledge regarding the scholarly exploration of the technologies, information/knowledge, and smart 
systems in educational administration and leadership. It provides a holistic, systematic, and comprehensive paradigm. Featuring a wide range of topics such as technology leadership in schools, technology integration in educational administration, and professional development, this book is ideal for school administrators, educational leaders, principals, IT consultants, educational software developers, academicians, researchers, professionals, educational policymakers, educators, and students.

\section{REVIEW OF THE BOOK}

The topics addressed by the authors of 16 chapters are as follow:

Chapter 1: Managing the Utilization of Technologies in Adult Education, Training, and Administration: The Case Study of Turkish MoNE by Mehmet Durnali. In Chapter 1, The chapter aims to investigate and discuss the technologies in Turkey's adult education system in a holistic, systematic way and within a framework with a theoretical basis for the use of the computer, the internet, and web-based technologies in adult education, training, and administration.

\section{Chapter 2: Administering Education and Training Through a Web-Based System: E-}

Curriculum by Tuncer Susam, Mehmet Durnali and Şenol Orakci. The chapter aims to describe e-Curriculum System of the Turkish Ministry of National Education (MoNE) in the context of administering education and training. The system, as a web-based educational administration tool, its benefits to administering, and importance of it were introduced at first.

Chapter 3: Technology for Classroom Management by Pinar Ayyildiz. The chapter aims to resort to technology highlighting the positive links between technology use in the classroom and management practices with a view to sharing some of the existing practices. Educational policies should be scrutinized to provide the optimum - if not the best - conditions for learners of every level with the help of incorporating 'suitable' educational technologies in light of the contexts where teaching and learning take place.

Chapter 4: Technology Leadership in Turkish Schools: A Systematic Review by Selahattin Turan, Mahmut Polatcan and Ramazan Cansoy. In Chapter 4, the authors systematically 
evaluate theses and articles that were published between the years 2000-2019 in Turkey related to school technology leadership in terms of their topics, methods, results, and recommendations.

\section{Chapter 5: Contribution of EMIS Platforms to Education Management and Recent} Applications by Mehmet Akif Ocak and Abdullah Alper Efe. In Chapter 5, the authors investigate the effect of educational management information systems (EMIS), which has a great importance in educational organizations. This chapter focuses on data process, analysis, synthesis, and design process of educational management information systems. This chapter, in depth, argues data storage, accuracy, planning, scalability, and transparency issues of EMIS systems. The focus is on how using EMIS systems helps educational administrators and decision makers as well as educational systems and economy.

Chapter 6: An Evaluation on the Management Processes of FATIH Project by Mehmet Akif Ocak and Abdullah Alper Efe. In Chapter 6, the authors investigate the FATIH Project in terms of educational administration and management processes. An extended literature review is conducted on how decision makers and administrators contribute the diffusion of FATIH Project and evoke necessary changes to transform education in classroom discourse and pedagogy.

Chapter 7: Technology Integration in Educational Administration by Gozde SezenGultekin and Nazire Burcin Hamutoglu. In Chapter 7, the authors start with overview on the current situation of education by referring to educational policies, development plans, international reports and contemporary applications of educational policies, and continues with addressing the definition, application areas, examples and next generation applications of technology integration at national and international levels within the scope of educational policies and development plans.

Chapter 8: Knowledge Management for Education Administrators by Ayça Kaya. In Chapter 8 , the author presents how knowledge management benefits schools when applied in an ecological framework by practicing upon the business theories of information management and knowledge management. 
Chapter 9: Information and Communication Technologies Literacy: Planning of Teachers' Information and Communication Technologies Training in Turkey by Ömür

Çoban. In Chapter 9, the author evaluates the teacher trainings given within the scope of the FATIH Project. The research focuses on training planners, trainers, and training areas to evaluate the training of the project.

Chapter 10 : Re-Establishing the School in the Light of Information Technology by Süheyla Bozkurt. In Chapter 10, the author opens the discussion of the concept of education and school that emerged as a result of the changes in information technologies and to provide insight into the future educational institutions.

\section{Chapter 11: Social Media Integration in Educational Administration as Information and} Smart Systems: Digital Literacy for Economic, Social, and Political Engagement in Namibia by Sadrag Panduleni Shihomeka and Helena N. Amadhila. Chapter 11 covers discussions on social media technologies that are being used as channels to foster various developments. The chapter used the integrated knowledge management cycle to explain how individuals are being developed economically, socially and politically through social media technologies.

Chapter 12: Gamification in Classroom Management by Murat Topal and Gozde SezenGultekin. In Chapter 12, the authors focus on the topic of gamification in classroom management. In this context, firstly, the definition, characteristics, theories of class management, and the strategies used in classroom management are defined, and then gamification as the next generation strategy is discussed.

Chapter 13: Sub-Dimensions in the Management of Open and Distance Learning by Hakan Altinpulluk. In Chapter 13, the author examines the management dimension in ODL systems in all aspects, supported by reports from reputable organizations and other studies in the literature. The chapter also describes the financing, marketing steps, information systems, benchmarking, quality and accreditation processes of the ODL institutions' management in terms of various components from those in the on-campus educational institutions and have a hierarchical structure within themselves. 


\section{Chapter 14: Shaping School Culture With Technology: Impact of Being an eTwinning}

School on Its Climate by Lamia Büşra Yeşil. In Chapter 14, the author discusses the impact of using technology on school culture along with its effects on the organizational climate. Accordingly, the views of 11 school administrators about integrating technology to the school culture and their preferences on using web 2.0 tools as a leader are presented.

\section{Chapter 15: Effect of Administration Support on Teachers' ICT Utilization in the} Malaysian Context by Simin Ghavifekr and Tan Yi Quan. In Chapter 15, the authors presents a comprehensive review of the relevant literature regarding ICT utilization and Administrative supportsin education settings. In addition, this chapter elaborates on the relevant theories to technology use and administrative supports and their key dimensions.

Chapter 16: Web-Based Responsive Mobile Learning (M-Learning) Design by Alaattin Parlakkılıç. In Chapter 16, the author presents a conceptual review on mobile learning as an initiative to leverage ubiquitous mobile technology for the adoption or augmentation of knowledge, behaviors, or skills through education, training, or performance support while the mobility of the learner may be independent of time, location, and space. The chapter also discusses the 5 steps responsive design for m-learning contexts that can be used across platforms and offers design of courses according to relevant instructional strategies.

\section{CONCLUSION}

This book attempts to assist educators, administrators and leaders to share some attempts in developing a clear understanding of various ICT-based learning approaches and pedagogical models via technology utilization to improve learning experiences, developing skills, competencies, creativity and critical thinking. Moreover, this book aims at developing students' digital understanding while they utilize technology to adapt to new learning contexts. 
About the Author(s)

\section{Can Güldüren}

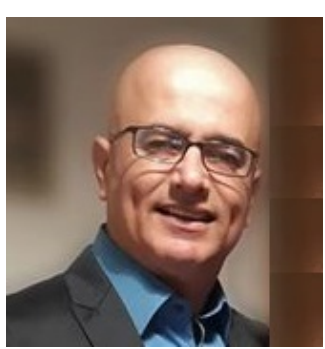

Can Güldüren is an assistant professor in the Department of Computer Technologies at Ufuk University, Turkey. After graduation from Army Academy he also completed his information systems education in Computer Engineering and Information Technology, Middle East Technical University/ Turkey. Güldüren holds an MA degree in Management and Organization in Selçuk University. Güldüren holds an MA and a Ph.D. degree in Computer Education and Instructional Technologies in Ankara University. His research interests lie broadly in information security, web programming, educational social networks, Augmented Reality, Artificial Intelligence and Virtual Reality, health informatics, e- learning, assistive technology, new learning technologies, personal learning environments (PLEs), technology-supported practices, and use of ICT in education.

Mailing Address: Ufuk University, Vocational School, Department of Computer Technologies, 06836, Ankara, Turkey. Contact Number: +90 31265867488

E-mail: can.gulduren@ufuk.edu.tr

\section{REFERENCES}

Durnali, M. (Eds.) (2019). Utilizing Technology, Knowledge, and Smart Systems in Educational Administration and Leadership. Hershey, PA: IGI Global. 